\title{
¿EVANGELIZANDO LA ÚLTIMA GENERACIÓN?
}

\author{
Pereyra, Mario \\ Universidad de Montemorelos, México \\ mariorpereyra@hotmail.com \\ Fecha de recepción: Abril 2013 \\ Fecha de aceptación y versión final: Mayo 2013
}

Resumen: $\mid$ Se exponen las características distintivas de las últimas etapas históricas del desarrollo de la cultura: modernidad, posmodernidad e hipermodernidad. Enfatiza aspectos distintivos de la personalidad en la hipermodernidad, como el estrés permanente, la violencia, la inseguridad, la vigilancia, la desconfianza, el hiperindividualismo y el hipernarcisismo. Se considera dos pasajes biblicos claves que describen la sociedad del fin, $2 \mathrm{Ti}$ moteo 3:1-9 y la descripción simbólica del Apocalipsis 18:1-8. Aunque son géneros literarios disímiles hay coincidencia en su descripción de la generación escatológica, como personas violentas, egoistas, narcisistas, simuladoras e individualistas. Finalmente, se discute cómo evangelizar a esa generación. El consejo paulino es no involucrarse con esa gente, sino evitarlos; sin embargo, Apocalipsis distingue dentro de Babilonia a personas que pueden escuchar la voz de Dios, e invita a llamarlas para que abandonen las prácticas pervertidas y se entreguen a Dios. La estrategia misionera es hacer consciente del destino terrorifico que le espera, al ser humano corrupto y depravado si permanece en Babilonia, para que tome la decisión correcta.

Palabras claves: Hipermodernidad, escatología, personalidad del fin, evangelización 
It describes the distinctive features of the latest historical stages of culture: modernity, postmodernity and hypermodernity. It emphasizes distinctive features of the personality in the hypermodernity, such as permanent stress, violence, insecurity, surveillance, distrust, hyperindividualism and hypernarcisismo. Then it addressed the biblical text to consider two key passages that describe the order of society, the picture painted by the apostle Paul in $2 \mathrm{Ti}$ mothy 3:1-9 and the symbolic description at Revelation 18:1-8. Although dissimilar genres, these texts agree in the eschatological generation, as selfish, narcissistic, violent, simulators, and individualistic people who can become corrupt and depraved. Finally, we discuss how to evangelize that generation, considering what would be the most suitable missionary program. Strikingly, the Pauline advice is not to get involved with these people, but to avoid them, however, the book of Revelations recognizes people in Babylon who may be sensitive to the voice of God, and calls them to abandon perverted practices and surrender to God. The mission is to make people conscious of the terrifying fate that awaits them if they remain in Babylon so that they can make the right decision.

Keywords: Hypermodernity, eschatology, personality in end of time, evangelism 
"Deberiamos estudiar las grandes señales que nos hablan de los tiempos en que vivimos. Es evidente que nos encontramos muy cerca de la culminación de la historia de esta tierra, y cualquier cosa de naturaleza mundanal debería ocupar un lugar secundario al servicio de Dios"1.

\section{Modernidad, Posmoderni- dad e Hipermodernidad}

Los historiadores dividen la historia en cuatro grandes épocas: antigua, medieval, moderna y contemporánea. Por su parte, los filósofos ${ }^{2}$, sociólogos ${ }^{3}$ y antropólogos culturales, ${ }^{4}$ suelen excluir la época contemporánea

1 Elena G. de White, Exaltad a Jesús (Buenos Aires: Asociación Casa Editora Sudamericana, 1988), 354.

2 G. Vattimo, El fin de la modernidad (Barcelona: Gedisa, 2000).

3 Gilles Lipovetsky y Sébastien Charles, Los tiempos hipermodernos, trad. Antonio P. Moya (Barcelona: Editorial Anagrama, S.A., 2006).

4 Marc A. Auge, Los "No Lugares": Espacios del Anonimato: Una Antropología de la Sobremodernidad, trad. Margarita N. Mizraji (Barcelona: Gedisa, Editorial, S.A., 1996). refiriéndose a las últimas épocas como modernidad, posmodernidad e hipermodernidad u otros términos afines. ${ }^{5}$ Más allá del debate de los términos, ${ }^{6}$ el hecho reconocido por los pensadores es que, en las últimas décadas, se han producido cambios estructurales en las condiciones de vida del mundo actual, que demandan un análisis serio para determinar si se identifican con los signos revelados por las profecías escatológicas.

La modernidad se desarroló durante los siglos XIX y XX, promovió la evidencia objetiva, la utilidad racional, el desarrollo científico y el descubrimiento de las leyes de la naturaleza. Domi-

5 Algunos términos afines para estas últimas épocas son: “Ultramodernidad", José A. Marina, Crónicas de la ultramodernidad (Barcelona: Anagrama, 2004). "Modernidad líquida", Zygmunt Bauman, Modernidad líquida, trad. Mirta A. Rosenberg (México: Fondo de Cultura Económica, 2003). "Transmodernidad", Rosa M. ${ }^{a}$ Rodríguez Magda, Transmodernidad (Vivaldi: Anthropos Editorial 2004). "Sobremodernidad". Auge.

6 Nicolás A. Casullo, ed. El Debate modernidad-posmodernidad, 2da ed. (Buenos Aires: Retórica Ediciones, 2004). 
nó el argumento del progreso y la mecanización, además de un marcado optimismo en el desarrollo científico-tecnológico, fe en la razón, como fundamento de la orientación social, la creencia mítica en el progreso indefinido y el determinismo histórico que prometía revoluciones sociales, sometidas a leyes científicas de cumplimiento inexorable.

De esta forma anunciaban la inminencia de la emancipación del hombre de toda forma de dominio y el pasaje del reino de la necesidad, al de la libertad. Se afirma la validez única del conocimiento científico, la secularización de la vida, la devaluación de la dimensión religiosa y mitológica de la existencia, el despliegue de la técnica moderna, como el paradigma del desarrollo humano. El siglo XIX fue un siglo revolucionario. En efecto, en ese momento se produjo el florecimiento del capitalismo con la Revolución Industrial, nacio el mercado global y el poder del Estado pasó a manos de la burguesía.
Con la publicación, La Condición Posmoderna de Jean-Francois Lyotard, en 1979, el concepto de posmodernidad se difundió rápidamente, imponiéndose la idea de un nuevo escenario cultural donde actúan las sociedades occidentales y el resto del mundo que sigue bajo su influjo. Significó un quiebre con los grandes proyectos políticos, el fracaso de los ideales revolucionarios que marcaron la historia de la modernidad desde el siglo XVIII y el nacimiento de un nuevo tipo de sociedad individualista, centrada en la vida presente, que privilegiaba el consumo y el hedonismo. Es la era de Narciso, de la contemplación con devoción de la propia imagen. El período posmoderno, señala el advenimiento de una temporalidad social inédita, caracterizada por la primacía del aquí y el ahora, abandonando lo social en beneficio de lo privado. Por supuesto, la fiebre consumista de satisfacciones inmediatas se acrecentó.

El derrumbe del optimismo ingenuo en el progreso indefi- 
nido y de las utopías sociales en mundos paradisiacos, ${ }^{7}$ dieron paso a los escepticismos más radicales. Surgieron los totalitarismos, el racismo, la intolerancia política, los genocidios. El hombre volvió a ser "el lobo del hombre”. Auschwitz, Gaza, la guerra en Afganistán e Irak, como tantos otros sucesos violentos desmintieron la creencia que el avance de la ciencia y la tecnología eran portadoras de paz y confort; la violencia continuó vigente y más activa que nunca, con manifestaciones inéditas de crueldad y destructividad. Por eso se ha llamado a la posmodernidad la época del desencanto.

Se renuncia a las utopías y a la idea de progreso. El futuro pierde valor, haciendo que a los individuos solo les interese vivir el presente. Con la aparición de

7 Tommasso Campanella, La ciudad del sol, trad. Emilio G. Estebanez (Madrid: Ediciones Akal, 2006); F. Bacon, La nueva Atlántida (España: Zero S.A., 1971); W. Morris, Notícias de lugar nenhum: ou uma época de tranqüilidade. Um romance utópico (São Paulo: Editora Fundação Perseu Abramo, 2002); H.G. Wells, A Modern Utopia (New York: Penguin Group, 2005). las tarjetas de crédito se impone la fórmula: "Goce hoy, pague mañana”, que sustituye la fórmula decimonona de "Ahorre hoy para asegurar el futuro". Los procesos de personalización triunfan. Las grandes instituciones, como la Iglesia, pierden influencia. Se hace culto al cuerpo y la liberación personal.

Otros rasgos distintivos de la posmodernidad es "el advenimiento de la cultura de la imagen, de la prioridad del objeto telepresente. De alguna manera, la televisión y el zapping se constituyen en protagonistas centrales de la cultura, una especie de "gran sacerdote electrónico" 0 escuela básica donde la "alfabetización mediática" se impone "por encima de la alfabetización de la letra". ${ }^{9}$ En este contexto, se asiste a la hegemonía de la seducción y el simulacro ${ }^{10}$ que

8 Beatriz Sarlo, Escenas de la vida posmoderna (Buenos Aires: Editorial Ariel, 1996), 114.

9 Ibíd., 135.

10 J. Baudrillard, De la seducción (Madrid: Editorial Cátedra, 1989); J. Baudrillard, Cultura y simulacro (Barcelona: Kairós, 1993). 
exhiben modelos y famosos, en los escenarios del espectáculo.

Este fenómeno de aparición de parámetros socioculturales innovadores ha generado una profunda crisis de identidad en el hombre posmoderno, el cual se estructura bajo nuevas creencias y valores. No todo es resplandores y flashes, también prevalece un clima de violencia e inseguridad en todos los niveles de la cultura, que ha producido una ruptura de los vínculos de solidaridad y fraternidad. Toda esta situación ha promovido nuevas patologías físicas, psicológicas y de personalidad, donde se destaca las adicciones, la depresión y la paranoia”. ${ }^{11}$

Pero la posmodernidad ya murió aseguran autores como Feinmann y Vattimo. ${ }^{12}$ Se entiende que la posmodernidad "se desintegró" y "ya no parece capaz de

11 M. Pereyra y E. Espinosa, La posmodernidad desde la perspectiva profética (Entre Ríos, Argentina: Editorial Bienestar Psicológico, 2000), 21.

12 J.P. Feinmann, La filosofía y el barro de la historia (Buenos Aires: Planeta Editores, 2008); Vattimo. dar cuenta de los cambios más recientemente producidos en la sociedad contemporánea", 13 siendo sustituida por la hipermodernidad. ${ }^{14}$ Esta nueva etapa se caracteriza por el exceso, un crecimiento fuera de límites en todas las esferas de la vida, por ejemplo: en la biotecnología, la cirugía estética, la conquista del espacio, los mails, los viajes aéreos y la pornografía. Una lógica de espiral infinita que también se manifiesta en fenómenos, como la obesidad, las adicciones de todo tipo, la aceleración de

13 N. Aubert, "L'urgence, symptôme de l'hypermodernité: de la quête de sens à la recherche de sensations", Communication et organisation 29, (2006): 11.

14 G. Lipovetsky y C. Sébastien, Los tiempos hipermodernos (Barcelona: Editorial Anagrama, 2006); G. Lipovetsky y J. Serroy, La pantalla global: Cultura mediática y cine en la era hipermoderna (Barcelona: Editorial Anagrama, 2009); G. Lipovetsky, La felicidad paradójica: Ensayo sobre la sociedad de hiperconsumo (Barcelona: Editorial Anagrama, 2007); G. Lipovetsky, La sociedad de la decepción: Entrevista con Bertrand Richard (Barcelona: Editorial Anagrama, 2008); N. Aubert, L'individu hypermoderne (Paris: Erés, 2004); F. Ascher, Le mangeur hypermoderne: Une figure de l'individu éclectique (Paris: Odile-Jacob, 2005). 
los medios y la invasión de las pantallas. ${ }^{15}$

En la segunda década del siglo XXI se observa el predominio de la tecnología más que de las ciencias. Asistimos a un proceso de exacerbación sin límites del capitalismo y el consumismo, en el marco de la hegemonía de los mercados, la ultraviolencia, el terrorismo y el hiperindividualismo. La sociedad hipermoderna está llevada por una escalada de excesos, de lo superlativo, de ir más a prisa; "la escalada paroxística del 'siempre más' se ha introducido en todos los ámbitos del conjunto colectivo". 16 Un escenario caracterizado por los extremos y el descontrol, por "compras compulsivas, endeudamiento, ciberdependencias, toxicomanías, prácticas aditivas de todo tipo, anarquía de los comportamientos alimentarios, individualismo desbocado $\mathrm{y}$ caótico". ${ }^{17}$

15 Lipovetsky y Serroy hablan del cine, TV, PC, GPS, DVD, celulares y otros medios. Véase, Lipovetsky y Serroy.

16 Lipovetsky y Sébastien, 58.

17 Lipovetsky,Lasociedaddeladecep-
La hipermodernidad es paradójica. Por un lado, es una sociedad seducida por lo frívolo y lo superfluo, como la moda y el lujo, los espectáculos de las grandes estrellas de la música y del deporte, en tanto por otro, se "ha reemplazado la fe en el progreso... por una confianza inestable, fluctuante, variable según los acontecimientos y las circunstancias". ${ }^{18}$ La posmodernidad fue más relajada, habitada por la despreocupación, la apatía y la indiferencia. En cambio en la hipermodernidad se vive en estrés permanente, con todo tipo de trastornos psicosomáticos, ansiedades, depresiones y suicidios. "Cuanto más a prisa se va, menos tiempo se tiene", ${ }^{19}$ más impotencia, más vulnerabilidad psicológica y desvaloración de sí mismo. Predomina un estado de inquietud ante el porvenir, que se percibe lleno de incertidumbres y riesgos. "En el universo inseguro, caótico y atomizado de la hipermodernidad

ción: Entrevista con Bertrand Richard, 119.

18 Lipovetsky y Sébastien, 74.

19 Ibíd., 82. 
aumentan igualmente las necesidades de unidad y de sentido, de seguridad, de identidad comunitaria: es la nueva oportunidad de las religiones". ${ }^{20}$ Asistimos, también, a un auge de las religiones, porque ellas dan sentido a la vida, construyen identidades y proporcionan la convicción de la realización personal. La modernidad rechazaba las creencias religiosas, la posmodernidad las toleraba, en tanto, la hipermodernidad las busca.

En el Cuadro 1 presentamos las características más importantes de las tres etapas reseñadas anteriormente en base a doce parámetros principales, con el propósito de contrastar como ha ido transformándose la cultura desde el siglo XVIII a la actualidad.

\section{La psicología del hombre hipermoderno}

De los doce criterios que perfilan los rasgos definitorios de cada una de las etapas mencionadas (ver Cuadro 1), los pri-

$20 \quad$ Ibíd., 99. meros seis presentan aspectos generales de la cultura (filosofía, economía, religión, etc.), en tanto, los últimos seis se refieren a manifestaciones sociales y humanas, es decir, aquellas que describen características de la personalidad en las diferentes generaciones. ¿Cómo podríamos delinear el perfil del hombre actual? ¿Cuáles son sus rasgos distintivos?

Como dijimos más arriba, en "la sociedad hipermoderna todo está exacerbado, compelido al exceso, hasta sus límites", ${ }^{21}$ ese exceso se manifiesta en el incremento de la violencia, en el hiperconsumo, en la ampliación desmedida de los mercados, en la competencia despiadada, en la búsqueda insaciable del placer, en el avance sin límites de la tecnología y las investigaciones, además de prácticamente todas las áreas de la cultura. Esta situación ha producido "una modificación profunda de nuestros

21 Así lo asegura Nicole Aubert en su libro. Véase, Aubert, L'individu hypermoderne. 
Cuadro 1: Características principales de cada etapa ${ }^{22}$

\begin{tabular}{|c|c|c|}
\hline $\begin{array}{l}\text { MODERNIDAD } \\
\text { (S.XVIII-1980) }\end{array}$ & $\begin{array}{l}\text { POSMODERNIDAD (1980. } \\
\text { 2001) }\end{array}$ & $\begin{array}{l}\text { HIPERMODERNIDAD } \\
\text { (2001 en adelante) }\end{array}$ \\
\hline * Idea de progreso & * Confusión & ${ }^{*}$ Exceso y descontrol \\
\hline${ }^{*}$ Fascinación por el futuro & * Desencanto del futuro & * Inquietud por el futuro \\
\hline $\begin{array}{l}\text { * Hipoconsumo (consumir lo } \\
\text { necesario) }\end{array}$ & $\begin{array}{l}\text { * Consumismo (consumir lo } \\
\text { innecesario) }\end{array}$ & $\begin{array}{l}* \text { Hiperconsumo (consumir } \\
\text { compulsivamente) }\end{array}$ \\
\hline $\begin{array}{l}\text { * Obsesión por el dominio de } \\
\text { la naturaleza (control de las en- } \\
\text { fermedades, etc.) }\end{array}$ & $\begin{array}{l}\text { * Conciencia de la destruc- } \\
\text { ción (contaminación, etc.) }\end{array}$ & $\begin{array}{l}\text { * Obsesión por miedo a la des- } \\
\text { trucción (terrorismo, catástro- } \\
\text { fes, epidemias) }\end{array}$ \\
\hline $\begin{array}{l}\text { * Regionalismos, nacionalis- } \\
\text { mos }\end{array}$ & * Globalización (económica) & $\begin{array}{l}\text { * Planetarización de los cam- } \\
\text { bios (social, etc.) }\end{array}$ \\
\hline $\begin{array}{l}\text { * Desvalorización de las religio- } \\
\text { nes (Secularización) }\end{array}$ & $\begin{array}{l}\text { * Tolerancia por las creencias } \\
\text { religiosas }\end{array}$ & * Auge de las religiones \\
\hline * Tranquilidad & * Despreocupación & * Estrés permanente \\
\hline * Seguridad & * Seguridad-inseguridad & * Inseguridad \\
\hline $\begin{array}{l}\text { * Reconocimiento de los dere- } \\
\text { chos personales }\end{array}$ & * Sociedad de la vigilancia & * Sociedad de la hipervigilancia \\
\hline * Confianza & ${ }^{*}$ Indiferencia & * Desconfianza \\
\hline $\begin{array}{l}\text { *Abnegación (diversión mode- } \\
\text { rada) }\end{array}$ & $\begin{array}{l}\text { * Narcisismo (búsqueda de } \\
\text { placeres) }\end{array}$ & $\begin{array}{l}\text { * Hipernarcisismo (viajar, di- } \\
\text { vertirse, no renunciar a nada) }\end{array}$ \\
\hline $\begin{array}{l}\text { * Interés por lo social (el bien } \\
\text { público) }\end{array}$ & $\begin{array}{l}\text { * Individualismo (no interesa } \\
\text { el bien público) }\end{array}$ & $\begin{array}{l}\text { * Hiperindividualismo (total } \\
\text { desinterés por el bien público) }\end{array}$ \\
\hline
\end{tabular}

comportamientos y la imposibilidad de vivir los valores a largo tiempo". 23

22 Ibíd; Lipovetsky, La felicidad paradójica: Ensayo sobre la sociedad de hiperconsumo; A. Medina, A las puertas de la eternidad (México: GEMA Editores, 2008), 301.

23 Ibíd.
Esas exigencias de "siempre más", de productividad obsesiva, de tener que correr todo el día para cumplir con las demandas, genera una sensación de nunca llegar, de nunca alcanzar el "Top level", temiendo siempre una posible expulsión, un despi- 
do, la muerte empresarial o el fracaso. De allí el estrés permanente que lleva inexorablemente al desgaste interno, al riesgo de estar "burn out" (síndrome del "quemado" o agotamiento). Freudenberger afirma,

Las personas a veces sufren incendios al igual que los inmuebles. Bajo el efecto de la tensión que produce la vida de nuestro complejo mundo, sus recursos internos acaban por consumirse como si estuvieran bajo la acción de las llamas, dejando tan solo un inmenso vacío en el interior aun cuando la apariencia externa parezca más o menos intacta. $^{24}$

Sin embargo, a la larga empiezan a manifestarse los síntomas por medio de contracturas intensas, dolores musculares, tensión en los hombros, dolores de columna, taquicardias, sensación de ahogo, caída de cabello, problemas digestivos, gastritis,

24 H. Freudenberger, L'épuisement professionnel: La Brûlure interne (Gaétan: Morin Éditeur. , 1987). úlceras, insomnios, impotencia o desgano sexual. Son los gemidos del cuerpo, como grita su malestar, un clamor que debe ser escuchado si pretendemos gozar de una buena calidad de vida.

La misma Nicole Aubert ${ }^{25}$ ha expuesto cuáles son las patologías físicas y psíquicas que caracterizan al individuo hipermoderno, que por supuesto, son a hechura del funcionamiento de la sociedad.

Por un lado, están las "patolo51 gías de lazo", como son las adicciones a substancias psicoactivas (drogas ilícitas, alcohol y tabaco) destinadas a favorecer el ritmo de las actividades crecientes, las patologías alimentarias, como la obesidad o la anorexia, ${ }^{26}$ que son formas de experimentar los límites del cuerpo. Por otro lado, están las patologías del "sobrecalentamiento", que son causadas por el hiperfuncionamiento al que se

25 N. Aubert, "L'individu hypermoderne et ses pathologies", L'Information Psychiatrique 82, (2006): 605-10.

26 Ascher. 
ven obligados los individuos que sobrepasan sus límites y que sucumben en síndromes ansiosos, estados de agotamiento ("burn out"), y de algún tipo de depresión u otro trastorno mental.

Se ha dicho que la vida social en la era hipermoderna se construye sobre cuatro grandes principios organizadores, a saber: la tecnociencia, el mercado, la democracia y el individuo.

Como hemos dicho, el individuo hipermoderno vive dentro

52 del instante, en un presente que se vive con cierta urgencia. Esta relación con el tiempo plantea la cuestión de la relación con el otro, ya que la construcción de los vínculos implica tiempo. Los sentimientos se alimentan de una historia, de memorias y de promesas. Cuando se vive en lo instantáneo y de sensaciones, el hipermoderno practica encuentros breves e intercambiables.

El otro aparece como objeto de satisfacción de un placer y no en una dinámica de auténtico intercambio. Así, los lazos son superficiales, como lo es en general en la vida que es light, leve, con escasa consistencia. De allí los índices en aumento de los divorcios, abandonos y relaciones transitorias o precarias.

Otra de las características de la sociedad actual es el imperio de la cultura de la violencia que afecta todos los órdenes, a nivel político (guerras, revoluciones, revueltas, etc.), social (por ej., delincuencia urbana), familiar y personal. Basta con leer los diarios todos los días para descubrir que vivimos presa de una vorágine de violencia que nos absorbe y nos arrastra a acciones irracionales. Se ha vuelto casi un hábito perverso que algún desquiciado o excéntrico tome un arma y embista en una escuela, universidad o centro público para matar gente en forma indiscriminada, incluso niños como ocurrió el 14 de diciembre del 2012 en Newtown, Connecticut, USA, cuando Adam Lanza, de 20 años, irrumpió en una escuela y a sangre fría mató a tiros 
a 20 niños de 6 años y 8 adultos, para después quitarse la vida.

Otra cara más amistosa de la sociedad actual es el narcisismo. En 1989, Christopher Lasch, escribió el best-seller, La cultura del narcisismo y posteriormente Gilles Lipovetsky, ${ }^{27}$ denominó la "era de Narciso" a la época actual, convirtiendo a Narciso en símbolo de la cultura. ¿Por qué ese mítico personaje ha sido convertido en emblema del hombre contemporáneo? Según la leyenda, Narciso era un joven muy hermoso y vanidoso que un día al inclinarse en una cisterna para beber, vio su rostro reflejado y se enamoró de sí mismo. Una versión afirma que al contemplarse en el agua, quiso abrazar su propia imagen, ahogándose en el intento. Según el manual de diagnósticos de los trastornos mentales de la American Psychiatric Association, el DSM-IV describe a los narcisistas como arrogantes, engreídos,

27 G. Lipovetsky, El crepúsculo del deber: La ética indolora de los nuevos tiempos democráticos (Barcelona: Editorial Anagrama, 1993). con fantasías grandiosas de sí mismos y sobrevaloración de sus logros, necesitados de ser admirados constantemente $\mathrm{y}$ esperando un trato preferencial continuo. Están convencidos de merecer mucho más de lo que reciben. Se preocupan por parecer y mantener su juventud. Son insensibles a las necesidades y problemas de los demás. En resumen, son envidiosos, orgullosos, hipersensibles a la valoración de la gente y viven obsesionados por las fantasías de éxito, poder y belleza.

Ciertamente, en nuestros días estamos asistiendo a la presencia de este tipo exacerbado de individualismo egoísta que solo busca su propia satisfacción y placer sin interesarse por más nada. Predomina la filosofía de "haced tu voluntad", "no te preocupes" o "trata de pasarla bien”. Importa solo el deseo de bienestar y distracción. Con respecto al resto del mundo y los intereses ajenos, domina una total insensibilidad o indiferencia. Las grandes cuestiones filosófi- 
cas, religiosas, económicas o políticas apenas despiertan alguna curiosidad superficial.

Dios es un desconocido y se ha perdido el sentido de lo trascendente. Todas las "alturas" se hunden. Únicamente la esfera personal parece salir victoriosa de la apatía. Interesa el confort y la comodidad, preservar la situación material, cuidar la salud, desprenderse de los "complejos" y esperar las vacaciones. Es el ideal del hombre "light". Se trata de vivir en el presente, solo en el presente y no en función del pasado y del futuro. Vivir para sí mismo, olvidándose de las tradiciones, la posteridad y el juicio final.

La mayor parte de la gente vive frustrada e insatisfecha, con una importante carga de hostilidad, detrás de una máscara apergaminada de sociabilidad. El hombre de hoy es frío, duro, tenso, de mirada esquiva, con reacciones rígidas y estereotipadas; es hipersensible, desconfiado, vive a la defensiva y está pronto a atacar al mínimo motivo, con un gesto burlón, despreciativo o directamente con la palabra soez y brutalmente insultante. ¿Será esta la hora de la profecía? ¿Son los tiempos anunciados por la Palabra de Dios?

\section{El perfil de la generación escatológica}

En la última carta a Timoteo el apóstol Pablo propone a su joven colaborador la misión de proclamar la Palabra (2 Ti 1:8), dando una serie de recomendaciones y explicando los deberes que le corresponden al ministro del evangelio. Le demanda que sea diligente $(2: 15)$, honesto $(2: 21)$, sensato $(2: 7)$, que no haga nada de lo cual tenga que avergonzarse (2:15), que sea veraz, amable y generoso con todos (2:24). Ante el sufrimiento y la oposición le exhorta a resistir con valor y coraje las pruebas (2:3-10), también le pide no enredarse en discusiones estériles $(2: 14,16,17)$ y mantenerse firme en la enseñanza recibida (1:1314). Agrega a esos consejos personales, algunas advertencias de 
peligros que puede correr en su trabajo (3:1). En ese contexto, el apóstol parece ser llevado por la inspiración más allá de la situación histórica en que vive, para proyectarse a los "postreros días", realizando una descripción detallada de las características de las personas que prevalecerían en los tiempos escatológicos. Estas son sus palabras:

"También debes saber que en los últimos dias vendrán tiempos peligrosos. Habrán hombres amadores de si mismos, avaros, vanidosos, soberbios, blasfemos, desobedientes a los padres, ingratos, impios, sin afecto natural, implacables, calumniadores, sin templanza, crueles, enemigos de lo bueno, traidores, impetuosos, engreidos, amadores de los deleites más que de Dios, que tendrán apariencia de piedad, pero negarán la eficacia de ella. A esos, evitalos. De ellos son los que se meten en las casas y llevan cautivas a las mujercillas cargadas de pecados, arrastradas por diversas pasiones. Estas siempre están aprendiendo, pero nunca pueden llegar al conocimiento de la verdad. Y de la manera que Janes y Jambres resistieron a Moisés, asi también estos resisten a la verdad; hombres corruptos de entendimiento, réprobos en cuanto a la fe. Pero no irán más adelante, porque su insensatez será manifiesta a todos, como también lo fue la de aquellos. (2 Ti 3:1-9; R95).

El perfil de personalidad del hombre del fin diseñado por el apóstol, bajo la inspiración divina, corresponde con las características del hombre hipermoderno examinadas más arriba. En algunos puntos parecen imágenes calcadas, semejantes a las que se obtienen superponiendo figuras trasparentes para conformar la misma silueta. Consideremos el asunto en forma más detallada. Los rasgos más notables que se desprenden de la lúcida descripción paulina son los siguientes:

a) Individualistas o hiperindividualistas: "egoístas", dice el apóstol, aunque toda la descripción da a entender que son gente a quienes solo les importa sus propios intereses y satisfacer 
sus deseos, sin reconocer ninguna autoridad.

b) Hedonismo: los protagonistas del fin son "amadores de los deleites" y actúan "arrastrados por diversas pasiones”, están movidos por los placeres y la sensualidad "sin templanza" o control.

c) Narcisismo: la profecía los define como seres orgullosos, vanidosos, soberbios y "amadores de sí mismos".

d) Carácter "light" o superficial: son simuladores, presumidos, les gusta aparentar, "apariencia de piedad", y les interesan vanagloriarse de las cosas banales o frívolas.

e) Inestabilidad y descontrol: la profecía informa que no podrán dominar sus pasiones, destacando la intemperancia, la impetuosidad del comportamiento y el hecho de ser "arrastrados por diversas pasiones".

f) Violencia: es otra caracte- rística destacada ya que los define como "crueles", "implacables", "impetuosos", sin "afecto natural” o compasión, aborrecedores o "enemigos de todo lo bueno", que promueven un estado de inseguridad y altos niveles de peligrosidad.

g) Corrupción: son "hombres corruptos de entendimiento" y de comportamiento, ya que secuestran mujeres "cargadas de pecado", presumiblemente para dedicarlas a la prostitución u a otros negocios turbios.

h) Cultura adolescente: es de hacer notar que la profecía describe una población de hijos (al decir "desobedientes a los padres"), en otros términos, se trata de gente joven que ha perdido el rumbo de los valores superiores para comportarse en forma indigna y arbitraria.

i) Trastorno de identidad: se observa que son inma- 
duros, inconsistentes y desorientados en sus creencias, ya que por un lado aparentan ser religiosos y por otro "hablan en contra de Dios" y "no respetan la religión”.

La profecía destaca el aspecto religioso porque la religión jugará un rol preponderante en el fin. En ese sentido, la descripción paulina muestra un comportamiento ambiguo $\mathrm{O}$ ambivalente, ya que no se trata de irreligiosos o ateos, por el contrario, son personas que manifiestan piedad y adoptan una conducta religiosa, pero todo constituye una vil simulación, ya que en su fuero íntimo abominan la fe y rechazan a Dios. En definitiva, son personas hipócritas, corruptas y perversas. Cuando el apóstol advierte que serán "tiempos peligrosos", está sugiriendo estar en guardia contra ese tipo de individuos, ya que no son confiables, sino "traidores". Ese hecho de estar prevenidos contra el engaño implica una actitud suspicaz y desconfiada, a no ser ingenuos y creer fácilmente en las personas, lo que induce un clima de desconfianza generalizada, que es otro rasgo significativo de la cultura del fin.

En síntesis, se trata de un cuadro deplorable de la degradación humana, una época cuando "los valores ya no valen" como dijera Nietzsche, donde los pensamientos, los sentimientos y los comportamientos aparecen distorsionados o desnaturalizados, una escenografía construida a la medida de la frivolidad y el cinismo, protagonizada por gente malpensada e insidiosa. Seguramente muchas de las características descritas por el apóstol Pablo han existido en todos los tiempos, pero si interpretamos como el perfil prevaleciente de una generación tenemos que reconocer coincidencias notables con las manifestaciones sociales de nuestros días hipermodernos, donde asistimos a la evanescencia de los valores y la descomposición moral. Esa interpretación nos lleva a entender el texto paulino como el cumplimiento 
de la profecía y el anuncio de estar instalados en los tiempos previos a la intervención divina en los destinos humanos.

Si bien 2 Timoteo 3:1-9 es la mejor descripción bíblica de la última generación del mundo, hay otro texto significativo que aporta nuevos datos sobre la sociedad del fin. Se encuentra en el capítulo 18 de Apocalipsis.

Como es sabido el género literario apocalíptico es diferente al de las epístolas paulinas, ya que presenta los mensajes en forma de metáforas o figuras simbólicas. En el capítulo mencionado la última generación se exhibe con la imagen de Babilonia, al final de su historia. Hay varias referencias a la antigua ciudad de Babilonia en Apocalipsis (14:8; $16: 19 ; 17: 5)$ que corresponden a distintos períodos de su existencia, la del capítulo 18 es la última, antes de que el cielo se abra y aparezca Cristo volviendo como un guerrero ecuestre victorioso, como aparece en el capítulo 19. Después de constituir el impe- rio más importante de su época, su momento de mayor gloria, Babilonia fue derrotada, entró en crisis y sucumbió. Al final fue un montón de escombros, habitada por animales depredadores, fieras rapaces y feroces (Is 13:21-22; Jer 50:39; 51:37). Esa etapa póstuma es descrita en forma patética y brutal, como una madriguera o "guarida" de "toda ave sucia y aborrecible" (18:2), movida por un "espíritu inmundo". Seguramente es un simbolismo muy sugestivo, pero ¿qué representa esa cueva llena de alimañas sanguinarias? ¿Qué quiere dar a entender el Apocalipsis con esa figura aterradora? ¿A quiénes se aplica?

Apocalipsis 18 es un texto que asigna gran importancia a la economía, ya que trata de "los comerciantes de la tierra que se enriquecieron" (v.3 NVI), del consumo excesivo que realizaron ("despilfarros en sus lujos", v.3) y de la debacle de la economía, que les origina grandes pérdidas, ya que expresan su pena y desconsuelo a través de una 
extensa letanía de lamentos (vs. 11-19). Sugiere que se trata de una economía de alcances mundiales, de mercado globalizado, donde un grupo de individuos sin escrúpulos -"aves de rapiña"-, estarían negociando grandes capitales para beneficios propios, operando desde las sombras de sus madrigueras perversas. Es común en economía, hablar de "fondos buitres", operados por grupos anónimos, que presionan a organizaciones y gobiernos (actúan sobre los "reyes de la tierra" dice 18:3) para obtener ganancias exorbitantes, constituyendo un cumplimiento de la profecía.

En este contexto, la "caída de Babilonia”, sería la bancarrota, el descalabro del sistema económico mundial, que llevaría a la ruina a millones que han puesto sus dineros en transacciones y negociados sucios. Esta Babilonia del fin estaría constituida por personas ávidas de dinero y poder, que utilizarían medios corruptos y perversos para conseguir sus objetivos, como el la- vado de dinero, la pornografía, la trata de mujeres y la prostitución, etc., etc., ya que dice literalmente el texto que "se han enriquecido con su excesiva lujuria" (18:3).

\section{¿Evangelizar la última generación del mundo?}

¿Cuál sería la estrategia para evangelizar la generación del fin? ¿Cómo se haría el abordaje? ¿Qué aconseja la Biblia respecto al trabajo con ese tipo de personas? Hay una clara indicación de cómo proceder en 2 Timoteo 3:5. Es un texto llamativo ya que no propone ningún programa evangelístico, y por el contrario, exhorta a no acercarse, a ir en dirección contraria a esas personas, a la inversa de lo que se entiende por evangelizar. Las diferentes versiones bíblicas de 2 Timoteo 3:5 son muy expresivas, lo registran en estos términos: "a los tales evita" (RVA), "evítalos" (RVC); "No tengas nada que ver con esa clase de gente" (DHH); "AAléjate de esa clase de individuos!” (NTV); “AApártate de esa 
gente!" (CST); "No te hagas amigo de esa clase de gente" (TLA); "iCon esa gente ni te metas!" (NVI); "no te metas con esa gente" (PDT). ${ }^{28}$ Pero, ¿Qué clase de evangelización es esta? ¿Acaso no hay que "predicar el evangelio a todo el mundo" (Mt 24:14; $\mathrm{Mr}$ 16:15)? ¿Será que para la última generación del mundo ya acabó el tiempo de gracia?

Quizás el texto de Apocalipsis 18 pueda dar una explicación más esclarecedora. ¿Hay alguna referencia sobre la evangelización a Babilonia? ¿Cuál es la estrategia misionera para convertir a Babilonia? En realidad no existe ningún programa misionero para evangelizar a Babilonia, que es igual a la clase de personas mencionadas por $\mathrm{Pa}-$ blo. Babilonia está desahuciada

28 Las abreviaturas corresponden a las siguientes versiones traducidas al español de la Biblia: RVA=Reina Valera Antigua; RVC=Reina Valera Contemporánea; $\mathrm{DHH}=$ Dios Habla Hoy; NTV=Nueva Traducción Viviente; CST=Nueva Versión Internacional; TLA=Traducción en el lenguaje actual; NVI=Nueva Versión Internacional; PDT=Palabra de Dios para Todos. de la gracia divina por voluntad propia, está condenada a muerte, solo falta el cumplimiento de su espantoso castigo. Sin embargo, Babilonia contiene personas engañadas, que todavía pueden ser sensibles a la voz de Dios, a las cuales se les hace un llamado dramático y conmovedor:

"Luego oí otra voz del cielo que decía: 'Salgan de ella, pueblo mío, para que no sean cómplices de sus pecados, ni los alcance ninguna de sus plagas; pues sus pecados se han amontonado hasta el cielo, y de sus injusticias se ha acordado Dios. Páguenle con la misma moneda; denle el doble de lo que ha cometido, y en la misma copa en que ella preparó bebida mézclenle una doble porción. En la medida en que ella se entregó a la vanagloria y al arrogante lujo denle tormento y aflicción; porque en su corazón se jacta: 'Estoy sentada como reina; no soy viuda ni sufriré jamás.' Por eso, en un solo día le sobrevendrán sus plagas: pestilencia, aflicción y hambre. Será consumida por el fuego, porque 
poderoso es el Señor Dios que la juzga'” (Ap 18:4-8).

Es llamativo que Dios no esté dispuesto a entrar en Babilonia como lo está para entrar en Laodicea (Ap 3:20), que también forma parte de la generación del fin. En el caso de Babilonia, la estrategia salvadora consiste en "salir", en responder al llamado, en ejercer la voluntad para abandonar los comportamientos corruptos de Babilonia y cambiar de vida. Mientras se está involucrado con las prácticas babilónicas y no se toma la decisión y la acción de renunciar y apartarse, no se estará en condiciones de alcanzar la salvación. El texto bíblico da a entender que es necesario dar a conocer el fin que les aguarda a quienes están en Babilonia, que tomen la decisión con plena conciencia del destino de seguir en Babilonia o de entregarse a Dios.

Todas las evidencias señalan que estamos bajo la mirada de la profecía que hablaba de la gente y la cultura que precedería la venida del Mesías. Sin embargo, aunque la descripción apocalíptica es implacable y aterradora no tenemos por qué inquietarnos, ya que el itinerario dantesco no culmina en las profundidades del infierno, sino por el contrario, en el cielo. La profecía abre un horizonte de promesa auspicioso con el anuncio de un mundo mejor y auténticamente feliz. Eso nos reconforta, anima y hace mirar el futuro con esperanza.

\section{Bibliografía}

Ascher, F. Le mangeur hypermoderne: Une figure de l'individu éclectique. Paris: OdileJacob, 2005.

Aubert, N. L'individu hypermoderne. Paris: Erés, 2004.

"L'urgence, symptôme de l'hypermodernité: de la quête de sens à la recherche de sensations".. Communication et organisation 29, (2006): 11-21.

Aubert, N. . "L'individu hypermoderne et ses pathologies". L'Information Psychiatrique 82, (2006): 605-10.

Auge, Marc A. Los "No Lugares": Espacios del Anonimato: Una Antropología de la Sobremodernidad. Traducido por Margarita N. Mizraji. Barcelona: Gedisa, Editorial, S.A., 1996.

Bacon, F. La nueva Atlántida. España: Zero 
S.A., 1971.

Baudrillard, J. De la seducción. Madrid: Editorial Cátedra, 1989. Cultura y simulacro. Barcelona: Kairós, 1993.

Bauman, Zygmunt. Modernidad líquida. Traducido por Mirta A. Rosenberg. México: Fondo de Cultura Económica, 2003.

Campanella, Tommasso. La ciudad del sol. Traducido por Emilio G. Estebanez. Madrid: Ediciones Akal, 2006.

Casullo, Nicolás A., ed. El Debate modernidad-posmodernidad. Buenos Aires: Retórica Ediciones, 2004.

Feinmann, J.P. La filosofía y el barro de la historia. Buenos Aires: Planeta Editores, 2008.

Freudenberger, H. L'épuisement professionnel: La Brûlure interne. Gaétan: Morin Éditeur., 1987.

Lipovetsky, G. El crepúsculo del deber: La ética indolora de los nuevos tiempos democráticos. Barcelona: Editorial Anagrama, 1993.

La felicidad paradójica: Ensayo sobre la sociedad de hiperconsumo. Barcelona: Editorial Anagrama, 2007. . La sociedad de la decepción: Entrevista con Bertrand Richard. Barcelona: Editorial Anagrama, 2008.

Lipovetsky, G., y C. Sébastien. Los tiempos hipermodernos. Barcelona: Editorial Ana- grama, 2006.

Lipovetsky, G., y J. Serroy. La pantalla global: Cultura mediática y cine en la era hipermoderna. Barcelona: Editorial Anagrama, 2009.

Lipovetsky, Gilles, y Sébastien Charles. Los tiempos hipermodernos. Traducido por Antonio P. Moya. Barcelona: Editorial Anagrama, S.A., 2006.

Marina, José A. Crónicas de la ultramodernidad. Barcelona: Anagrama, 2004.

Medina, A. A las puertas de la eternidad. México: GEMA Editores, 2008.

Morris, W. Noticias de lugar nenhum: ou uma época de tranqüilidade. Um romance utópico. São Paulo: Editora Fundação Perseu Abramo, 2002.

Pereyra, M., y E. Espinosa. La posmodernidad desde la perspectiva profética. Entre Rios, Argentina: Editorial Bienestar Psicológico, 2000.

Rodríguez Magda, Rosa M.a. Transmodernidad. Vivaldi: Anthropos Editorial 2004.

Sarlo, Beatriz. Escenas de la vida posmoderna. Buenos Aires: Editorial Ariel, 1996.

Vattimo, G. El fin de la modernidad. Barcelona: Gedisa, 2000.

Wells, H.G. A Modern Utopia. New York: Penguin Group, 2005.

White, Elena G. de. Exaltad a Jesús. Buenos Aires: Asociación Casa Editora Sudamericana, 1988. 